
ISSN : 2615-1995, E-ISSN : 2615-0654

J. Madani., Vol. 3, No. 2, September 2020 (259 - 266)

C2018 Lembaga Kajian Demokrasi

dan Pemberdayaan Masyarakat (LKD-PM)

DOI : https://doi.org/10.33753/madani.v3i2.120

\title{
Pengaruh Budaya Organisasi, Lingkungan Kerja, dan Disiplin Kerja Terhadap Kepuasan Kerja Karyawan Pada PT Panca Putra Madani
}

\author{
Sigit Purnomo \\ Fakultas Ekonomi, Universitas Pamulang \\ dosen02152@unpam.ac.id \\ Agung Tri Putranto \\ Fakultas Ekonomi, Universitas Pamulang \\ dosen02047@unpam.ac.id
}

\begin{abstract}
Abstrak
Tujuan penelitian ini untuk mengetahui pengaruh antara teori-teori dengan fakta-fakta yang berkaitan dengan variabel independen, yakni budaya organisasi, lingkungan kerja dan disiplin kerja serta variabel dependen, yakni kepuasan kerja. Pendekatan metode kuantitatif dengan bentuk sebab akibat yaitu asosiatif (kausal). Jumlah populasi dan sampel dari riset ini sebanyak 70 responden, yang berarti semua populasi akan dijadikan responden dengan memakai non-probability sampling yakni biasa disebut dengan sampel jenuh. Dalam menganalisis data penulis menggunakan statistik inferensial, yaitu dengan menguji kelayakan data-data yang akan diteliti yang meliputi Uji Valid (validitas) dan Uji Reliabel (reliabililitas), selanjutnya Uji Asumsi Klasik seperti uji normalitas, uji multikolinieritas dan uji heteroskedastisitas. Adapun dalam pengujian Hipotesis menggunakan Uji Fisher (uji F) dan pengujian $t$ (uji $t$ ), selanjutnya pengujian koefisien determinasi, serta pengujian analisis regresi linier berganda. Nilai yang diperoleh dalam penelitian ini, pengujian Hipotesis didapat uji F (secara simultan) variabel bebas (Budaya organisasi, Lingkungan kerjaan dan Disiplin kerja) mendapatkan nilai yang besar dari pada ftabel yang artinya terjadi pengaruh secara positif serta signifikan terhadap variabel dependen (Kepuasan Kerja) dimana nilai $F_{\text {hitung }}>F_{\text {tabel }}(9.337>2.51$ ). Hasil uji parsial budaya organisasi terhadap kepuasan kerja mempunyai pengaruh positif dan signifikan, di mana nilai $t_{\text {hitung }}$ $>t_{\text {tabel }}(3.325>1.99)$. Lingkungan Kerja terhadap kepuasan kerja mempunyai pengaruh positif dan signifikan, di mana nilai $t_{\text {hitung }}>t_{\text {tabel }}(4.264>1.99)$. Disiplin kerja terhadap kepuasan kerja berpengaruh positif dan signifikan, di mana nilai $t_{\text {hitung }}>t_{\text {tabel }}(2.364>1.99)$. Besaran sumbangsih variabel bebas yaitu budaya organisasi, lingkungan kerja dan disiplin kerja terhadap kepuasan kerja didapat angka Adjusted R Square sebesar 0.266 atau 26,6\% dimana 73,4\% merupakan komponen-komponen lain diluar riset ini. Dan terakhir dalam uji persamaan regresi linier berganda menghasilkan $Y=7.438+0.087 X_{1}+0.137 X_{2}+0,089 X_{3}$.
\end{abstract}

Kata Kunci : Budaya Organisasi, Lingkungan Kerja, Disiplin Kerja, kepuasan Kerja

\begin{abstract}
The purpose of this research is to determine the influence between theories and facts related to the independent variables, namely organizational culture, work environment and work discipline as well as the dependent variable, namely job satisfaction. The quantitative method approach with the form of cause and effect is associative (causal). The total population and sample of this research were 70 respondents, which means that all populations will be made respondents using non-probability sampling, which is commonly referred to as saturated samples. In analyzing the data, the writer uses inferential statistics, namely by testing the feasibility of the data to be studied which includes the validity test (validity) and the reliable test (reliability), then the
\end{abstract}


classical assumption test such as normality test, multicollinearity test and heteroscedasticity test. As for the hypothesis testing using the Fisher test (F test) and t test ( $t$ test), then testing the coefficient of determination, as well as testing multiple linear regression analysis. The value obtained in this study, Hypothesis testing, obtained that the F test (simultaneously) the independent variables (organizational culture, work environment and work discipline) get a greater value than the table which means that there is a positive and significant influence on the dependent variable (Job Satisfaction). where the value of $F_{\text {count }}>F_{\text {table }}(9.337>2.51)$. The results of the partial test of organizational culture on job satisfaction have a positive and significant effect, where the value of $t_{\text {count }}>$ $t_{\text {table }}(3.325>1.99)$. Work environment on job satisfaction has a positive and significant effect, where the value of $t_{\text {count }}>t_{\text {table }}(4.264>1.99)$. Work discipline on job satisfaction has a positive and significant effect, where the value of $t_{\text {count }}>t_{\text {table }}(2.364>1.99)$. The contribution of the independent variables, namely organizational culture, work environment and work discipline on job satisfaction, shows the Adjusted R Square figure of 0.266 or $26.6 \%$, where $73.4 \%$ are other components outside of this research. And finally, in the multiple linear regression equation test it produces $Y=7.438+0.087 X_{1}+0.137 X_{2}+0.089 X_{3}$.

Keywords: Organizational culture, Work environment, Work discipline, Work satisfaction

\section{PENDAHULUAN}

Berbicara mengenai permasalahan yang dihadapi oleh bangsa Indonesia saat ini adalah penanganan terhadap rendahnya kualitas sumber daya manusia dalam menghadapipersaingandunia usaha dan pasar bebas. Keseluruhan sumber daya manusia yang besar jika dapat diperdayagunakan baik secara efektif dan efisien, maka akan bermanfaat untuk menunjang gerak lajunya perekonomian nasional yang berkelanjutan. Melimpahnya sumber daya manusia yang ada saat ini mengharuskan berpikir secara seksama yaitu bagaimana dapat memanfaatkan sumber daya manusia secara optimal.

Pembangunan Infrastruktur sedang dalam proses, potensi Sumber Daya Alam sudah tidak diragukan, tetapi kualitas Sumber Daya Manusia masih diragukan. Kualitas Sumber Daya Manusia di Indonesia masih kurang. Hal ini menjadi tidak seimbang antar jumlah sumber daya manusia (SDM) dengan pembangunan infrastruktur. Ketidakseimbangan antara pembangunan infrastruktur dan sumber daya manusia akan menjadi penghambat bagi provinsi di Indonesia dalam proses pengembangannya. Tidak menjadi masalah dalam pemenuhan kebutuhan sarana dan prasarana dengan melakukan pembangunan infrastruktur secara efektif dan terus-menerus, tetapi ada satu hal yang penting untuk segera dilakukan yaitu pembangunan Sumber Daya Manusia (SDM) yang dilakukan pemerintah.

Penelitian ini dilakukan pada PT Panca
Putra Madani merupakan salah satu perusahaan manufacture dan fabrikasi yang sudah menjalankan usaha bisnisnya sejak tahun 2006. Salah satu perusahaan yang sedang berkembang dalam dunia usaha manufacture dan fabrikasi khususnya di dalam pembuatan dan perbaikan hydraulic di Bekasi Jawa Barat. Pengamatan yang penulis lakukan terungkap suatu fenomena di mana kesuksesan yang dimiliki PT Panca Putra Madani saat ini masih terdapat adanya rasa ketidakpuasan yang dirasakan karyawan, hal ini terlihat dari pemberian tunjangan dan insentif yang dirasakan karyawan tidak sesuai dengan apa yang diharapkan sehingga tumbuh perasaan tidak puas atas apa yang didapat dari hasil kerja yang diberikan kepada perusahaan.

Berdasarkan data di atas penetapan penghasilan yang diberikan pada PT. Panca Putra Madani diberikan pegawai sesuai dengan jabatan dan prestasi dari pegawai dengan tujuan menciptakan pegawai yang mampu bekerja dengan baik. Peningkatan penghasilan yang diiringi dengan kenaikan jabatan dimaksudkan dalam upaya penciptaan kepuasan kerja terhadap kinerja yang diberikan karyawan, namun hal itu masih saja dirasakan belum mampu memberikan kepuasan. Jika kondisi seorang karyawan mengharapkan kepuasan dalam kerja, maka seorang karyawan itupun akan berupaya semaksimal mungkin menyelesaikan pekerjaannya, yang akhirnya akan menghasilkan kualitas pelayanan yang tinggi, hasil produksi yang 
baik dan pencapaian tujuan perusahaan.

Hasil pengamatan awal yang penulis lakukan juga berhubungan dengan bagaimana perusahaan membangun suatu budaya organisasi yang mencerminkan pemiliki perusahaan itu sendiri. Budaya organisasi menjadi sebuah tuntunan bagi setiap elemen organisasi suatu perusahaan untuk membentuk sikap dan perilaku yang sesuai dengan visi dan misi perusahaan yang pada akhirnya menghasilkan sumber daya yang disiplin, mempunyai integritas yang tinggi, bekerja dengan penuh tanggung jawab, dan berkualitas secara intelektual maupun softskill yang dimiliki. Tujuan dari penerapan budaya organisasi adalah agar seluruh individu dalam perusahaan atau organisasi mematuhi dan berpedoman pada sistem nilai keyakinan dan norma-norma yang berlaku dalam suatu perusahaan dan hal tersebut belum mampu diimplementasikan secara maksimal oleh sebagian besar karyawan PT Panca Putra Madani.

Pencapaian tujuan perusahaan tentu tidak lepas dari bagaimana kenyamanan pelaku-pelaku di dalam organisasi itu sendiri yang dalam hal ini adalah karyawan perusahaan PT Panca Putra Madani. Faktor yang menjadi salah satu bagaimana kepuasan kerja karyawan meningkat ataupun menurun adalah lingkungan kerja yang ada di perusahaan. Apabila perusahaan tidak dapat mengontrol lingkungan organisasinya secara internal, maka yang akan terjadi adalah konflik antar sesama karyawan ataupun konflik antar divisi (bagian) yang akhirnya akan berpengaruh pada peningkatan hasil kerja para karyawan. Perusahaan masih belum mampu untuk menciptakan suatu budaya di lingkungan kerja yang harmonis dan dinamis agar dapat meningkatkan kerjasama dan mempererat tali silaturahmi antar karyawan. Lingkungan kerja yang nyaman tidak dirasakan oleh pegawai pada PT Panca Putra Madani dan keadaan tersebut dapat terlihat dari AC dibeberapa ruangan tidak ada, ruang kerja banyak kertas yang berserakan, sirkulasi udara di ruang kerja masih ada yang pengap.

PT Panca Putra Madani merupakan perusahaan yang bergerak di bidang jasa manufaktur dan pabrikasi dalam perjalanan waktu tentu tidak dapat terhindar dari perubahan bisnis yang semakin memungkinkan persaingan secara terbuka di dalam berbagai sektor. Tuntutan persaingan yang terbuka mau tidak mau harus dipenuhi oleh perusahaan terutama dalam memperhatikan aspek sumber daya manusia (SDM) yang dimilikinya untuk dapat menciptakan karyawan yang profesional, tangguh, cerdas, dan berpandangan ke depan. Karyawan merupakan aset yang paling berharga yang dimiliki perusahaan dan harapan untuk memberikan kontribusi yang maksimal dari karyawan atas fungsi serta perannya di perusahaan masih terlihat berjalan di tempat sehingga menghambat kemajuan PT Panca Putra Madani dalam menghadapi persaingan usaha yang sejenis saat ini.

Berdasarkan hasil wawancara dengan Manajer Produksi pada PT Panca Putri Madani dalam kaitannya dengan motivasi yang diberikan kepada karyawan. Beliau menyatakan bahwa bentuk pemberian motivasi yang diberikan pada karyawan dapat berupa insentif, bonus, dan lain-lain. Di mana pemberian tersebut hanya diberikan kepada karyawan yang berprestasi dan pencapaian hasil produksi yang sudah diselesaikan tepat waktu, jadi tidak untuk semua karyawan. Hal itu tidak sesuai dengan kenyataannya, pemberian tersebut tidak membuat dampak yang cukup berarti bagi karyawan untuk meningkatkan motivasinya karena karyawan beranggapan bahwa pemberian insentif tersebut diberikan bergilir kepada setiap karyawan dan setiap karyawan pasti mendapatkannya.

Kepuasan kerja yang menurun tentu dapat dipengaruhi oleh motivasi kerja yang terdapat di dalam diri karyawan itu sendiri dan juga orangorang disekitar karyawan seperti pimpinan ataupun atasan memberikan dorongan kepada bawahan. Ketika dorongan untuk bekerja maksimal sudah mulai turun akibatnya akan menjadi penyulut tingkat kedisiplinan kerja karyawan itu sendiri. Permasalahan lain yang terdapat pada PT Panca Putra Madani adalah berkaitan dengan disiplin kerja karyawan yang rendah. Para pimpinan telah berusaha mengatasi kedisiplinan karyawan dengan menerapkan aturan yang cukup ketat dan membuat beberapa sanksi jika me- 
lakukan kesalahan. Namun pada kenyataannya hal tersebut masih saja tidak membuat karyawan sadar dalam mematuhi aturan yang ditetapkan. Hal ini dibuktikan dengan data pemotongan gaji jika melakukan kesalahan kedisiplinan, salah satu contohnya adalah disiplin dalam hal waktu kerja.

Berdasarkan uraian tersebut di atas diharapkan PT Panca Putra Madani dapat memberikan kepuasan dalam bekerja dengan mencari jalan keluar yang terbaik dalam menyelesaikan permasalahan dan konflik yang terjadi. Oleh karena itu penulis tertarik untuk melakukan penelitian terkait bagaimana fenomena yang terdapat di PT Panca Putra Madani Bekasi Jawa Barat dapat dibuktikan dan terdapat kesesuaian dengan teori yang ada.

\section{Pembatasan Masalah}

Dengan keterbatasan penelitian diatas maka penulis ingin membatasi permasalahan dari fenomena yang terjadi pada pemaparan diatas agar mudah dipahami dan dapat memberikan batasan-batasan pada penulisan ini berdasarkan pada judul penelitian diatas, yaitu pengaruh budaya organisasi, lingkungan kerja dan disiplin kerja terhadap kepuasan kerja karyawan pada PT Panca Putra Madani.

\section{METODE}

Penelitian ini menggunakan sumber data utama yaitu kuesioner yang disebarkan kepada keseluruhan responden dan berikutnya dilakukan tabulasi frekuensi angka berdasarkan interprestasi skala likert. Penulis menggunakan metode kuantitatif dengan bentuk asosiatif yakni bersifat kausal atau sebab akibat sebagai model penelitian yang dikembangkan. Di mana keberadaan variabel penyebab diteliti yaitu $\mathrm{X}_{1}$ (budaya organisasi), $\mathrm{X}_{2}$ (lingkungan kerja), $\mathrm{X}_{3}$ (disiplin kerja) sehingga dapat diketahui pengaruh besaran nilainya, di mana kepuasan kerja $(\mathrm{Y})$ adalah variabel independen.

\section{Populasi dan Sampel}

Lingkup objek yang diteliti meliputi seluruh karyawan PT Panca Putra Madani dengan total populasi yaitu sebanyak 70 responden. Penelitian ini memberlakukan generalisasi di mana sampel penelitian untuk mewakili populasi penelitian dan dalam penetapan jumlah sampel penelitian maka teknik yang digunakan adalah Nonprobability Sampling dengan jenis sampel jenuh. Dengan begitu populasi penelitian secara keseluruhan yang berjumlah 70 responden/karyawan penulis gunakan sebagai sampel penelitian.

\section{HASIL dan PEMBAHASAN}

Bersumber pada data jawaban responden yakni kuesioner dalam riset yang telah olah dan hitung serta diberlakukan transformasi, data ordinal ke data rasio, menjadikan syarat mutlak dalam perhitungan statistik yang setidaknya data berbentuk rasio selanjutnya akan diolah kembali dengan bantuan perhitungan SPSS.25 for windows. Maka didapat hasil penelitian sebagai berikut:

\section{Uji Instrumen (Validitas dan Reliabilitas)}

Uji Validasi dilakukan untuk mengukur sah atau tidaknya indikator atau kuesioner dari masing-masing variabel. Pengujian dilakukan dengan membandingkan $\mathrm{r}_{\text {hitung }}$ dan $\mathrm{r}_{\text {tabel }}$. Kevalidan item pernyataan dari variabel-variabel peneltian yaitu budaya organisasi, lingkungan kerja, disiplin kerja, dan kepuasan kerja jika nilai $\mathrm{r}_{\text {hitung }}>\mathrm{r}_{\text {tabel }}$ sedangkan nilai $\mathrm{r}_{\text {tabel }}$ berdasarkan pedoman untuk uji dua arah (two tail) dengan tingkat toleransi sebesar 5\% (n-2) 70 - 2 = 68 dihasilkan nilai 0.235. Sedangkan untuk mengetahui data yang reliable dilakukan uji reliabilitas dengan taraf toleransi yang ditentukan bilamana koefisien Cronbach's Alpha $>$ 0,60 maka diyatakan reliable.

\section{Uji Validitas}

Untuk pengujian instrumen riset ini, terangkum dalam tabel 1 , hasil pengolahan data dengan menggunakan SPSS.22 hasil keseluruhan variabel-variabel riset ini dapat dilihat dari hasil dibawah ini.

\begin{tabular}{|c|c|c|c|}
\hline \multicolumn{4}{|c|}{ Tabel 1. Hasil Uji Validitas } \\
\hline \multicolumn{4}{|c|}{ Budaya Organisasi $\left(X_{1}\right)$} \\
\hline Pertanyaan & $r_{\text {hitung }}$ & $r_{\text {tebel }}$ & Keterangan \\
\hline Q1 & .765 & .235 & Valid \\
\hline
\end{tabular}




\begin{tabular}{|c|c|c|c|}
\hline Q2 & .821 & .235 & Valid \\
\hline Q3 & .676 & .235 & Valid \\
\hline Q4 & .403 & .235 & Valid \\
\hline Q5 & .685 & .235 & Valid \\
\hline Q6 & .742 & .235 & Valid \\
\hline Q7 & .655 & .235 & Valid \\
\hline Q8 & .769 & .235 & Valid \\
\hline Q9 & .759 & .235 & Valid \\
\hline Q10 & .741 & .235 & Valid \\
\hline Q11 & .662 & .235 & Valid \\
\hline \multicolumn{4}{|c|}{ Lingkungan Kerja $\left(X_{2}\right)$} \\
\hline Pertanyaan & $r_{\text {hitung }}$ & $r_{\text {tebel }}$ & Keterangan \\
\hline Q1 & .718 & .235 & Valid \\
\hline Q2 & .401 & .235 & Valid \\
\hline Q3 & .524 & .235 & Valid \\
\hline Q4 & .670 & .235 & Valid \\
\hline Q5 & .613 & .235 & Valid \\
\hline Q6 & .572 & .235 & Valid \\
\hline Q7 & .661 & .235 & Valid \\
\hline Q8 & .531 & .235 & Valid \\
\hline Q9 & .668 & .235 & Valid \\
\hline Q10 & .571 & .235 & Valid \\
\hline Q11 & .528 & .235 & Valid \\
\hline Q12 & .629 & .235 & Valid \\
\hline \multicolumn{4}{|c|}{ Disiplin kerja $\left(\mathrm{X}_{3}\right)$} \\
\hline Pertanyaan & $r_{\text {hitung }}$ & $r_{\text {tebel }}$ & Keterangan \\
\hline Q1 & .655 & .235 & Valid \\
\hline Q2 & .263 & .235 & Valid \\
\hline Q3 & .331 & .235 & Valid \\
\hline Q4 & .708 & .235 & Valid \\
\hline Q5 & .708 & .235 & Valid \\
\hline Q6 & .713 & .235 & Valid \\
\hline Q7 & .730 & .235 & Valid \\
\hline Q8 & .677 & .235 & Valid \\
\hline Q9 & .646 & .235 & Valid \\
\hline Q10 & .789 & .235 & Valid \\
\hline Q11 & .566 & .235 & Valid \\
\hline Q12 & .566 & .235 & Valid \\
\hline \multicolumn{4}{|c|}{ Kepuasan kerja (Y) } \\
\hline Pertanyaan & $r_{\text {hitung }}$ & $r_{\text {tebel }}$ & Keterangan \\
\hline Q1 & .586 & .235 & Valid \\
\hline Q2 & .640 & .235 & Valid \\
\hline Q3 & .410 & .235 & Valid \\
\hline Q4 & .632 & .235 & Valid \\
\hline Q5 & .594 & .235 & Valid \\
\hline Q6 & .644 & .235 & Valid \\
\hline
\end{tabular}

Mengacu pada tabel di atas hasil uji instrumen validitas secara keseluruhan nilai $\mathrm{r}_{\text {hitung }}$ dari setiap item pernyataan variabel penelitian yaitu budaya organisasi $\left(\mathrm{X}_{1}\right)$, lingkungan kerja $\left(\mathrm{X}_{2}\right)$, disiplin kerja $\left(\mathrm{X}_{3}\right)$, dan Kepuasan Kerja (Y) mempunyai nilai > $r_{\text {tabel }}(0,235)$, dapat diambil simpulan bahwa semua jawaban yang ada pada kuesioner dalam riset ini yaitu Valid.

\section{Uji Reliabilitas}

Tabel.2 menyajikan hasil pengujian reliabilitas dimana keseluruhan tanggapan responden berdasarkan uji statistik SPSS.22 adalah sebagai berikut.

\begin{tabular}{|l|c|c|}
\hline \multicolumn{1}{|c|}{ Tabel 2. Hasil Uji Reliabilitas } \\
\hline \multicolumn{1}{|c|}{ Item } & Cronbach's Alpha & Keterangan \\
\hline Budaya Organisasi $\left(\mathrm{X}_{1}\right)$ & .898 & reliabel \\
\hline Lingkungan Kerja $\left(\mathrm{X}_{2}\right)$ & .833 & reliabel \\
\hline Disiplin Kerja $\left(\mathrm{X}_{3}\right)$ & .847 & reliabel \\
\hline Kepuasan Kerja(Y) & .612 & reliabel \\
\hline
\end{tabular}

Kesimpulan dari tabel 2 di atas, maka seluruh hasil dan nilai Cronbach's Alpha lebih besar dari 0,60 yang berarti terdapat konsistensi hasil keseluruhan jawaban responden, sehingga dapat dilakukan untuk uji selanjutnya.

\section{Uji Asumsi Asumsi Klasik}

Dalam pengujian asumsi klasik ini dilakukan meliputi normalitas pada data residu, data multikolinieritas, dan heteroskedastisitas. Berikut diuraikan hasil uji asumsi klasik yang diterapkan sebagai syarat dalam memenuhi model regresi.

\subsection{Uji Normalitas Residu Kormogorov- Smirnov (KS)}

Dibawah ini merupakan hasil pengolahan statistik dengan menggunakan SPSS. 22 for windows untuk uji normalitas data residual dengan pendekatan Kolmogorov-Smirnov Test.

\begin{tabular}{|l|l|r|}
\hline \multicolumn{3}{|c|}{ Tabel 3. Uji Normalitas (1-Sampel KS Test) } \\
\hline \multicolumn{3}{|c|}{ One-Sample Kolmogorov-Smirnov Test } \\
\hline $\mathrm{N}$ & & $\begin{array}{c}\text { Unstandardized } \\
\text { Residual }\end{array}$ \\
\hline Normal Parameters, & & 70 \\
\hline Most Extreme Differences & Mean & .0000000 \\
\cline { 2 - 3 } & Std. Deviation & 2.45557945 \\
\hline & Absolute & .071 \\
\cline { 2 - 3 } & Positive & .054 \\
\cline { 2 - 3 } & Negative & -.071 \\
\hline Kolmogorov-Smirnov Z & & .593 \\
\hline Asymp. Sig. (2-tailed) & & .874 \\
\hline $\begin{array}{l}\text { a. Test distribution is Normal. } \\
\text { b. Calculated from data. }\end{array}$ & \\
\hline
\end{tabular}


Dari hasil uji Normalitas dengan metode Kolmogorov-Smirnov di atas Sig 0,05 untuk besarnya nilai Test Statistic diperoleh 0,593 dan nilai Sig 0,874. Yang dapat ditafsirkan nilai signifikansi lebih besar dari 0,05 yang berarti data residual berdistribusi normal.

\subsection{Uji Multikolinieritas}

Berdasar pada tabel 4 menunjukkan hasil pengujian multikolinieritas yang dijadikan acuan lain yang wajib terpenuhi, di mana hasil pengujian regresi mengharuskan tidak boleh ada korelasi yang sama pada variabel-variabel independen atau variabel bebas, hasilnya dapat tersaji sebagai berikut.

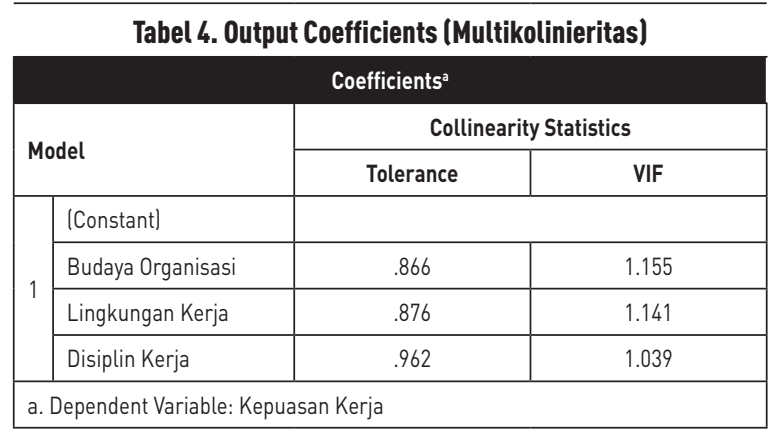

Pada tabel 4 diatas dapat dilihat bahwa nilai tolerance diperoleh nilai kurang dari 0.1 (tolerance $>0,1$ ). Dilain hasil, pada tabel 4 nilai VIF didapat lebih kecil dari 10 (VIF < 10). Dengan begitu gejala multikolinieritas tidak ditemukan pada model regresi dalam penelitian ini.

\subsection{Uji Heteroskedastisitas}

Yang diperoleh dari hasil uji heteroskedastisitas ini adalah untuk pembuktian apakah ditemukan gejala yang dapat menimbulkan heteroskedastisitas, untuk itu hasil dapat dijelaskan pada gambar.1 yang disajikan dalam bentuk Scatterplot.

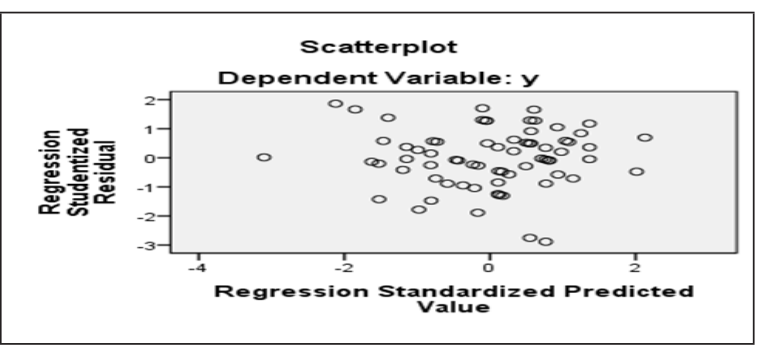

Gambar 1. Grafik Scatterplot (Heteroskedastisitas)
Dari gambar Scatterplot di atas menunjukkan bahwa titik-titik menyebar di atas dan dibawah angka 0 pada sumbu Y serta penyebaran titik-titik data tidak berpola, maka dapat disimpulkan bahwa tidak terjadi heteroskedastisitas.

\section{Uji Hipotesis}

\section{a. Persamaan Regresi Linier Berganda}

Hipotesis adalah dugaan terhadap hubungan antara dua variabel atau lebih. Atas dasar definisi tersebut dapat diartikan bahwa hipotesis adalah jawaban atau dugaan sementara yang harus di uji kebenarannya. Hipotesis penelitian di uji dengan menggunakan uji parsial dan uji simultan.

\begin{tabular}{|c|c|c|c|c|c|c|}
\hline \multicolumn{7}{|c|}{$\begin{array}{l}\text { Tabel 5. Output Regresi Linear Berganda } \\
\text { Budaya Organisasi }\left(X_{1}\right) \text { Lingkungan Kerja }\left(X_{2}\right) \text { dan } \\
\text { Disiplin Kerja }\left(X_{3}\right) \text { Terhadap Kepuasan Kerja (Y) }\end{array}$} \\
\hline \multicolumn{7}{|c|}{ Coefficients $^{\mathrm{a}}$} \\
\hline \multirow{2}{*}{\multicolumn{2}{|c|}{ Model }} & \multicolumn{2}{|c|}{$\begin{array}{l}\text { Unstandardized } \\
\text { Coefficients }\end{array}$} & \multirow{2}{*}{$\begin{array}{c}\begin{array}{c}\text { Standardized } \\
\text { Coefficients }\end{array} \\
\text { Beta }\end{array}$} & \multirow{2}{*}{$t$} & \multirow{2}{*}{ Sig. } \\
\hline & & B & $\begin{array}{l}\text { Std. } \\
\text { Error }\end{array}$ & & & \\
\hline \multirow{4}{*}{1} & (Constant) & 7.438 & 3.061 & & 2.430 & .018 \\
\hline & $x_{3}$ & .087 & .049 & .187 & 1.783 & .079 \\
\hline & $x_{2}$ & .173 & .053 & .359 & 3.255 & .002 \\
\hline & $x_{1}$ & .089 & .045 & .218 & 1.968 & .053 \\
\hline
\end{tabular}

Berdasarkan tabel Output di atas dapat dijelaskan bahwa, persamaan regresi linear berganda $\mathrm{Y}=\mathrm{a}+\mathrm{b}_{1} \mathrm{x}_{1}+\mathrm{b}_{2} \mathrm{x}_{2}+\mathrm{b}_{3} \mathrm{x}_{3}$ adalah $\mathrm{Y}=7,438+0,087\left(\mathrm{X}_{1}\right)+0,173\left(\mathrm{X}_{2}\right)$ $+0,089\left(X_{3}\right)$. Persamaan regresi ini dapat disimpulkan bahwa, terdapat pengaruh positif antara Budaya Organisasi $\left(\mathrm{X}_{1}\right)$, Lingkungan Kerja $\left(\mathrm{X}_{2}\right)$ dan Disiplin Kerja $\left(\mathrm{X}_{3}\right)$ Terhadap Kepuasan Kerja (Y).

Konstanta a $=7,438$ menunjukkan bahwa, nilai Kepuasan Kerja (Y) saat ini diasumsikan bernilai 7,438 satuan dengan asumsi variabel Budaya Organisasi $\left(\mathrm{X}_{1}\right)$, Lingkungan Kerja $\left(\mathrm{X}_{2}\right)$, Disiplin Kerja $\left(\mathrm{X}_{3}\right)$ dan Kepuasan Kerja (Y) bernilai tetap.

Konstanta $\mathrm{b}_{1} \mathrm{x}_{1}=0,087$ menunjukkan bahwa, jika terdapat kenaikan satu-satuan pada variabel Budaya Organisasi 
$\left(\mathrm{X}_{1}\right)$ maka nilai Kepuasan Kerja (Y) akan bertambah sebesar 0,087 satuan.

Konstanta $\mathrm{b}_{2} \mathrm{x}_{2}=0,173$ menunjukkan bahwa, jika terdapat kenaikan satu-satuan pada variabel Lingkungan Kerja $\left(\mathrm{X}_{2}\right)$ maka nilai Kepuasan Kerja (Y) akan bertambah sebesar 0,173 satuan.

Konstanta $\mathrm{b}_{3} \mathrm{x}_{3}=0,089$ menunjukkan bahwa, jika terdapat kenaikan satu-satuan pada variabel Disiplin Kerja (X3) maka nilai Kepuasan Kerja (Y) akan bertambah sebesar 0,089 satuan.

\section{b. Uji F (Uji Fisher)}

Dibawah ini akan disajikan hasil uji F, dimana data yang diperoleh menggambarkan nilai seberapa jauh pengaruh secara bersama-sama (simultan) antara variabel bebas (independen) dengan variabel terikat (dependen) yang tersaji pada tabel.6.

\begin{tabular}{|c|c|c|c|c|c|c|}
\hline \multicolumn{7}{|c|}{ Tabel 6. Output Uji Anova (Uji Fisher) } \\
\hline \multicolumn{7}{|c|}{ ANOVA ${ }^{a}$} \\
\hline \multicolumn{2}{|c|}{ Model } & $\begin{array}{l}\text { Sum of } \\
\text { Squares }\end{array}$ & Df & $\begin{array}{l}\text { Mean } \\
\text { Square }\end{array}$ & $\mathrm{F}$ & Sig. \\
\hline \multirow{3}{*}{1} & Regression & 176.582 & 3 & 58.861 & 9.337 & $.000^{\mathrm{b}}$ \\
\hline & Residual & 416.061 & 66 & 6.304 & & \\
\hline & Total & 592.643 & 69 & & & \\
\hline & $\begin{array}{l}\text { endent V } \\
\text { lictors: I }\end{array}$ & $X_{3}, X_{2}$ & & & & \\
\hline
\end{tabular}

Melihat tabel Output di atas dapat dijelaskan bahwa, $\mathrm{F}_{\text {hitung }} 9,337>\mathrm{F}_{\text {tabel }} 2,51$ atau probabilitas Sig 0,000 $<0,05$ maka $\mathrm{H}_{03}$ di tolak dan $\mathrm{H}_{\mathrm{az}}$ di terima artinya signifikan dengan demikian hipotesis yang diajukan menetapkan terdapat pengaruh positif dan signifikan secara bersama-sama antara Budaya Organisasi $\left(\mathrm{X}_{1}\right)$, Lingkungan Kerja $\left(\mathrm{X}_{2}\right)$ dan Disiplin Kerja $\left(\mathrm{X}_{3}\right)$ Terhadap Kepuasan Kerja (Y) pada karyawan PT Panca Putra Madani Bekasi.

\section{c. Uji T (Uji Parsial)}

Dibawah ini tabel 7, tabel. 8 dan tabel 9 merupakan hasil SPSS.22 untuk menguji secara sendiri-sendiri antara variabel bebas; budaya organisasi (X1), lingkungan kerja $\left(\mathrm{X}_{2}\right)$ dan disiplin kerja (X3) terhadap yang dipengaruhi kepuasan kerja (Y).

\begin{tabular}{|c|c|c|c|c|c|c|}
\hline \multicolumn{7}{|c|}{ Tabel 7. Budaya Organisasi Terhadap Kepuasan Kerja } \\
\hline \multirow{2}{*}{\multicolumn{2}{|c|}{ Model }} & \multicolumn{2}{|c|}{$\begin{array}{l}\text { Unstandardized } \\
\text { Coefficients }\end{array}$} & \multirow{2}{*}{$\begin{array}{c}\begin{array}{c}\text { Standardized } \\
\text { Coefficients }\end{array} \\
\text { Beta }\end{array}$} & \multirow{2}{*}{$t$} & \multirow{2}{*}{ Sig. } \\
\hline & & B & $\begin{array}{l}\text { Std. } \\
\text { Error }\end{array}$ & & & \\
\hline \multirow{2}{*}{1} & (Constant) & 16.606 & 1.929 & & 8.608 & .000 \\
\hline & $x_{1}$ & .153 & .046 & .374 & 3.325 & .001 \\
\hline
\end{tabular}

Tabel 8. Lingkungan Kerja Terhadap Kepuasan Kerja

\begin{tabular}{|c|c|c|c|c|c|c|}
\hline \multicolumn{7}{|c|}{ Coefficients $^{\mathrm{a}}$} \\
\hline \multirow{2}{*}{\multicolumn{2}{|c|}{ Model }} & \multicolumn{2}{|c|}{$\begin{array}{l}\text { Unstandardized } \\
\text { Coefficients }\end{array}$} & \multirow{3}{*}{$\begin{array}{c}\text { Standardized } \\
\text { Coefficients } \\
\text { Beta }\end{array}$} & \multirow{3}{*}{$\begin{array}{c}t \\
5.464\end{array}$} & \multirow{3}{*}{$\begin{array}{r}\text { Sig. } \\
.000\end{array}$} \\
\hline & & \multirow{2}{*}{$\begin{array}{l}\text { B } \\
12.928\end{array}$} & \multirow{2}{*}{$\begin{array}{c}\begin{array}{c}\text { Std. } \\
\text { Error }\end{array} \\
2.366\end{array}$} & & & \\
\hline & (Constant) & & & & & \\
\hline & $x_{2}$ & .221 & .052 & .459 & 4.264 & .000 \\
\hline
\end{tabular}

Tabel 9. Disiplin Kerja Terhadap Kepuasan Kerja

\begin{tabular}{|c|c|c|c|c|c|c|}
\hline \multicolumn{7}{|c|}{ Coefficients $^{\mathrm{a}}$} \\
\hline \multirow{2}{*}{\multicolumn{2}{|c|}{ Model }} & \multicolumn{2}{|c|}{$\begin{array}{l}\text { Unstandardized } \\
\text { Coefficients }\end{array}$} & \multirow{2}{*}{$\begin{array}{c}\text { Standardized } \\
\text { Coefficients }\end{array}$} & \multirow{2}{*}{$t$} & \multirow{2}{*}{ Sig. } \\
\hline & & B & $\begin{array}{l}\text { Std. } \\
\text { Error }\end{array}$ & & & \\
\hline \multirow{2}{*}{1} & (Constant) & 17.057 & 2.507 & & 6.804 & .000 \\
\hline & $X_{3}$ & .127 & .054 & .276 & 2.364 & .021 \\
\hline
\end{tabular}

Berdasarkan ketiga tabel output coefficients uji parsial variabel bebas terhadap variabel terikat dapat diambil kesimpulan bahwa keseluruhan Nilai $\mathrm{t}_{\text {hitung }}$ variabel Budaya Organisasi $\left(\mathrm{X}_{1}\right)$, Lingkungan Kerja $\left(\mathrm{X}_{2}\right)$, Disiplin Kerja $\left(\mathrm{X}_{3}\right)_{\text {mempunyai nilait }}$ hitung $_{\text {tabel }}>\mathrm{t}_{\text {ta }}, 99$ atau nilai Sig $<0,05$ dengan begitu terdapat pengaruh positif dan signifikan antara Budaya Organisasi $\left(\mathrm{X}_{1}\right)$, Lingkungan Kerja $\left(\mathrm{X}_{2}\right)$, Disiplin Kerja $\left(\mathrm{X}_{3}\right)$ terhadap Kepuasan Kerja (Y).

\section{SIMPULAN}

Dari pembahasan yang dipaparkan dan olah data di atas, maka penulis menarik kesimpulan dan saran-saran yang dapat digunakan sebagai acuan bagi penelitian selanjutnya. Berdasarkan rumusan masalah pertama dan pengujian statistik 
yang dilakukan, secara parsial hasil $(3,325>1,99)$ dengan Sig $(0,001<0,05)$. Artinya, pengaruh positif dan signifikan variabel bebas (budaya organisasi) terhadap variabel terikat (kepuasan kerja) terbukti. Berdasarkan rumusan masalah kedua dan pengujian statistik yang dilakukan, secara parsial hasil $\mathrm{t}_{\text {hitung }}>\mathrm{t}_{\text {tabel }}(4,264>1,99)$ dengan Sig $(0,000<0,05)$. Artinya, pengaruh positif dan signifikan variabel bebas (lingkungan kerja) terhadap variabel terikat (kepuasan kerja) terbukti. Berdasarkan rumusan masalah kedua dan pengujian statistik yang dilakukan, secara parsial hasil $\mathrm{t}_{\text {hitung }}>\mathrm{t}_{\text {tabel }}(2,364>1,99)$ dengan Sig $(0,000$ $<0,05)$. Artinya, pengaruh positif dan signifikan variabel bebas (disiplin kerja) terhadap variabel terikat (kepuasan kerja) terbukti. Berdasarkan rumusan masalah keempat dan pengujian statistik yang dilakukan, secara bersama-sama hasil $\mathrm{F}_{\text {hitung }}>\mathrm{F}_{\text {tabel }}(9,337>2,51)$ dengan Sig $(0,000<$ $0,05)$. Artinya, variabel-variabel bebas (budaya organisasi, lingkungan kerja dan disiplin kerja) secara bersama-sama terbukti berpengaruh positif dan signifikan terhadap variabel terikat kepuasan kerja.

\section{PENGHARGAAN}

Dalam kesempatan ini penulis ingin menghaturkan banyak terimakasih kepada seluruh pihak-pihakyang terkaitkhususnyaPTPancaPutra Madani yang sudah memberikan kesempatan bagi kami untuk meneliti pada perusahaan yang bapak dan ibu pimpin, serta pihak-pihak lain yang juga terlibat secara langsung maupun tidak langsung yang sudah memberikan masukan dan bimbingan sehingga penulis dapat menyelesaikan penelitian dan penulisan ini dengan baik. Terima kasih atas saran, masukan, dan bantuan, semoga penelitian ini bisa bermanfaat bagi semua pihak.

\section{DAFTAR PUSTAKA}

Arikunto, S. (2010). Prosedur Penelitian Suatu Pendekatan Praktek. Jakarta: PT. Rineka Cipta.

Dessler, G. (2012). Manjemen Sumber Daya Manusia. Edisi Kesembilan. Jilid II. Jakarta: PT. Indeks Kelompok Gramedia.
Djokosantoso, M. (2005). Budaya Organisasi Dalam Tantangan. Jakarta: PT. Elex Media Komputindo.

Ghozali, I. (2011). Aplikasi Analisis Multivariate Dengan Program IBM SPSS19. Cetakan Kelima. Semarang: Universitas Diponegoro.

Handoko, H T. (2011). Manajemen Personalia \& Sumber Daya Manusia. Cetakan kedelapan belas, Yogyakarta: BPFE.

Hasibuan, M. (2012). Manajemen Sumber Daya Manusia. Jakarta: PT. Bumi Aksara.

Ismainar, H. (2015). Administrasi Kesehatan Masyarakat. Jakarta: Deepublish.

Kuncoro, M. (2007). Metode Kuantiatif. Yoyakarta: STIM YKPN .

Mangkunegara, A.A. Anwar Prabu. (2006). MSDM. Bandung: PT. Remaja Rosda Karya.

Sedarmayanti. (2011). MSDM Reformasi Birokrasi dan Manajemen Pegawai Negeri Sipil. Bandung: PT. Refika Aditama.

Sunyoto, D.(2012). Manajemen danPengembangan Sumber Daya Manusia. Yogyakarta: Center for Academic Publishing Service.

Rivai, V. (2016). Kiat Memimpin Dalam Abad ke21. Jakarta: PT. Raja Grafindo Persada.

Simamora, H. (2004). Manajemen Sumber Daya Manusia. Edisi Kedua, Cetakan Kesembilan. Yogyakarta: YKPN.

Stoner, A. F. (2014). Manajemen Sumber Daya Manusia. Jakarta: Bumi Aksara.

Sugiyono. (2016). Metode Penelitian Kuantitatif Kualitatif dan R\&D. Bandung: Alfabeta.

Sunyoto, D. (2013). Manajemen Sumber Daya Manusia. Cetakan kedua. Yogyakarta. CAPS. Sutrisno, E. (2011). Manajemen Sumber Daya Manusia. Jakarta: Kencana.0020. 